\title{
Patient-reported outcomes of carpal tunnel syndrome surgery in a non-industrial area
}

\author{
Katarzyna Kogut ${ }^{1, A-D, F}$, Wojciech Michał Glinkowski ${ }^{2,3, A-F} \oplus$ \\ ${ }^{1}$ Medical Diagnostic Imaging Center, Puławy, Poland \\ ${ }^{2}$ Medical University, Warsaw, Poland \\ ${ }^{3}$ Polish Telemedicine and eHealth Society, Warsaw, Poland \\ A - Research concept and design, B - Collection and/or assembly of data, C - Data analysis and interpretation, \\ $D$ - Writing the article, E - Critical revision of the article, F - Final approval of article
}

Kogut K, Glinkowski WM. Patient-reported outcomes of carpal tunnel syndrome surgery in a non-industrial area. Ann Agric Environ Med. 2019; 26(2): 350-354. doi: 10.26444/aaem/99004

\begin{abstract}
Introduction and objective. This study aimed to determine the environmental conditions for the occurrence of carpal tunnel syndrome (CTS) in a non-industrial area, and patient-reported outcomes after surgical release.

Materials and method. This observational study utilized convenience sampling to screen 100 consecutive patients for carpal tunnel syndrome at the Orthopedic Clinic, using two questionnaires. Data were collected from the Disability of Arm Shoulder and Hand (DASH) questionnaire, and the PROMIS ${ }^{\circledast}$ (Patient-Reported Outcomes Measurement Information System) Upper Extremity and PROMIS ${ }^{\circledR}$ SF $3 a$ questionnaire (Pain Intensity). The relationship of various repetitive musculoskeletal disorders to CTS was validated by questionnaire scores, $\mathrm{PROMIS}{ }^{\circledR}$ T-score, and correlation coefficients.

Results. Finally, CTS was confirmed by electromyography in 69 patients (55 females and 14 males; average age: 47.5 years). Aging significantly influenced the occurrence of symptoms associated with pain (neck, thoracic, lower back, shoulder, and CTS $(p<0.001)$ ). Those employed for longer more frequently declared performing exercises to prevent overload pain $(p<0.001)$. DASH results significantly correlated with the PROMIS Upper Extremity score $(r=-0.64 ; p<0.05)$.

Conclusions. Geographical and environmental conditions indicate that even though working with a computer is described as an essential risk factor for CTS, the study group showed a predominance of elements that were unrelated to working at a computer. CTS also occurred among people working physically, and even among unemployed individuals. The existence of a statistically significant, strong, negative correlation $(r=-0.64 ; p<0.05)$ between the results obtained in the questionnaires DASH and PROMIS Upper Extremity has been demonstrated.
\end{abstract}

\section{Key words}

carpal tunnel syndrome, occupational disease, musculoskeletal pain, computers, Patient-reported outcomes, non-industrial area

\section{INTRODUCTION}

Carpal tunnel syndrome (CTS) is the most common peripheral nerve entrapment syndrome, and it frequently present in working-aged adults [1-6]. A recent meta-analysis suggested that excessive computer use, particularly mouse usage, might be a minor occupational risk factor for CTS [7].

The prevalence of the CTS in industrialized countries is estimated to be $0.2 \%$ among women and $0.05 \%$ in men in Piedmont Region, Italy [8], and $2.3 \%$ of the population of workers in the USA [9]. The prevalence was estimated between $7 \%-18 \%$ of the general adult population in the UK by Ferry at al. [10]. CTS is usually treated by surgical decompression with generally favourable long-lasting outcomes [11-15].

\section{OBJECTIVES}

The aims of this study were to determine the environmental conditions for the occurrence of CTS in a non-industrial area, and patient-reported outcomes after a single postoperative outpatient clinic visit using the Disability of Arm Shoulder

Address for correspondence: Wojciech Michał Glinkowski Medical University of Warsaw, Banacha 1a, 02-097 Warszawa, Poland

e-mail:w.glinkowski@gmail.com

Received: 21.07.2018; accepted: 16.10.2018; first published: 26.11.2018 and Hand (DASH) [16], and Patient-Reported Outcomes Measurement Information System (PROMIS ${ }^{\circledR}$ ) Upper Extremity and SF 3a questionnaires, and compare the results obtained using these two outcome instruments [17].

\section{MATERIALS AND METHOD}

The study included 100 consecutive patients observed in a specialist Orthopedic Clinic. The patients were informed about the purpose and methods of the study beforehand and signed informed consent to participate. During a visit to the out-patient clinic, patients filled in questionnaires under silent and focused conditions, in an independent research room without any influence from other people. Occupational risk related to the development of CTS was assessed based on the Repetitive Strain Injuries (RSI) questionnaire associated with computer use. The questionnaire was developed to identify syndromes associated with overload, including CTS, including CTS in people working at a computer [18]. The questionnaire was available via the Internet and has been active since 21 January 20125.

The study used the following research instruments (translated into Polish): PROMIS ${ }^{\circledast}$ Pain Intensity [19-26] (Short Form 3a); PROMIS ${ }^{\circledR}$ upper extremity $[17,27]$, and the widely used DASH $[16,28]$. The PROMIS ${ }^{\circledR}$ Pain Intensity 
(Short Form 3a v1) instrument was developed to assess the intensity of perceived pain. The Pain Intensity short form is usually used as a patient self-evaluation, independent of disease. It is based on the ability of the patient to provide relatively quick, quantitative pain intensity estimates. Most measures of pain intensity tend to be closely-related to one another. The Short Form 3a Pain Intensity instrument is used in adults. Translation into the Polish language was performed by FACITtrans using standardized PROMIS ${ }^{\circledast}$ methodology and was approved by the PROMIS ${ }^{\circledR}$ Statistical Center. The translation included two forward translations, one back-translation, three independent reviews, followed by pretesting [29]. The Patient-Reported Outcome Measurement Information System (PROMIS ${ }^{\circledast}$ ), funded by the National Institutes of Health, aims to provide clinicians and researchers with the access to efficient, precise, valid, and responsive adult-, and child-reported measures for physical, mental, and social well-being. PROMIS ${ }^{\circledR}$ tools measure what patients can do and how they feel. Health measurement instruments $\left(\mathrm{PROMIS}^{\circledR}\right.$ ) can be used as primary or secondary endpoints in clinical studies of the effectiveness of treatment. Together with traditional clinical measures of health, patient-oriented outcomes provide clinicians and researchers with important patient-reported information to better understand the influence of various treatments on their physical functioning and other symptoms they experience. All results generated through PROMIS ${ }^{\oplus}$ were analyzed by the scoring tool available online (www.healthmeasures.net) through the Assessment Center. The Assessment Center is a free online research management tool enabling researchers to create studyspecific websites for capturing participant data securely. This non-interventional study was approved by the institutional Review Board (Reference No. NR KB 22/12).

Statistical analysis was carried out using STATISTICA 12.0 software (StatSoft, Inc., Tulsa, OK, USA) [30]. Descriptive statistics were generated, and the data were subjected to Shapiro-Wilk testing for normality of variances. The differences between groups were assessed using the Wilcoxon matched pair test (dependent data), and the Mann-Whitney $\mathrm{U}$ and Kruskal-Wallis tests (independent data). For analysis of the correlation between measured parameters, the Spearman rank correlation was used. The internal correlation test was used to measure whether several items of PROMIS and DASH questionnaires produce similar scores. Differences were considered as significant with $\mathrm{P}<0.05$.

\section{RESULTS}

Reliable results from the questionnaires were obtained from 69 patients, comprising 55 women and 14 men, aged between 20-79 years (mean age 46 years). 21 respondents were aged between $51-60$ years, whereas young people, under 30 years of age $(n=10)$ accounted for only a small percentage.

Of the respondents, 30 did not work professionally for various reasons (either unemployed, pensioners, or retirees). Farmers and people working in the household were also among the respondents $(n=5)$. The largest group of patients $(n=53)$ had at least a high school education. 36 respondents worked at a computer, 21 of whom had worked with computers for 10-20 years, 13 respondents declared working with computers for less than 10 years, and only 2 respondents reported that they had been working at the computer for 30 years or longer. In the group of persons working at the computer, 16 worked 5-8 hours a day. Only 3 subjects declared more than 8 hours of work. Five people worked 1-4 hours per day. Professionally, the study group presented a high diversity, and computer work was not the dominant way of performing their job.

Employment history at the computer significantly influenced the occurrence of symptoms; the reported problems occurred in people with a longer employment history (specifically, pain-related symptoms: neck pain $(\mathrm{p}<0.001)$, thoracic back pain $(\mathrm{p}<0.001)$, lower back pain $(\mathrm{p}<0.001)$, shoulder pain $(\mathrm{p}<0.001)$, and CTS $(\mathrm{p}<0.001)$.

The group with a longer employment history more frequently declared performing exercises to prevent overload pain $(p<0.001)$. Breaks in work caused by CST were significantly more often reported in these patients $(\mathrm{p}<0.001)$.

DASH scores significantly correlated with the average intensity of the pain $(\mathrm{r}=0.86)$ and the level of pain at the moment of filling questionnaire $(r=0.58)$. Average pain level was strongly associated with pain occurring at the worst time.

Table 1. Spearman correlation coefficient for pain intensity scale before treatment (PROMIS ${ }^{\circledR}$ SF 3a Pain Intensity Short Form 3a responses)

\begin{tabular}{llccc}
\hline \multirow{2}{*}{ Variable } & \multicolumn{3}{c}{ Spearman's r correlation } \\
\cline { 2 - 4 } 1 & 1 & 2 & 3 \\
\hline 2 How intense was your pain at its worst? & - & 0.72 & 0.82 \\
\hline $3 \quad$ What is your level of pain right now? & 0.72 & - & 0.67 \\
\hline
\end{tabular}

Everyday activities selected in the study population hindered functioning in the social environment to a great extent. The obtained results were then used to identify correlated activities, which may have further had the greatest impact on the experienced pain.

A set of inter-correlated activities were observed in these results $(\mathrm{p}<0.05)$. The value of the relationships between responses had a strong, positive character $(r>0.5)$. Among the everyday activities, significantly positive correlations were observed for the following items at $\mathrm{p}<0.05$ : "Place an object on a shelf above your head" and "Push open a heavy door" $(\mathrm{r}=0.74)$. The detailed list of the most correlated activities tested by DASH questionnaire is shown in Table 2 .

Test results using the PROMIS ${ }^{\otimes}$ Short Form 3a (Pain Intensity) questionnaire were obtained from respondents before and after CTS treatment. Distribution of the tested variables was obtained using the Shapiro-Wilk test. Results of the PROMIS ${ }^{\oplus}$ Short Form $3 a$ (Pain Intensity) questionnaire were compared with the standardized results using the T-score.

Before treatment, an average T-score was 58. After the surgery, an average T-score significantly decreased to 40 , which means a decrease of the pain intensity and improvement after surgery (Fig. 1).

Quantitative distribution of patient response to a question about the level of pain intensity at the worst time before and after treatment is shown in Figure 2.

None of the respondents reported very strong pains after treatment, with 24 patients $(34.78 \%)$ reporting a total disappearance of pain, and no cases with very strong pain. After treatment, no deterioration of the physical conditions in the tested group was reported. Only 2 patients (3\%) showed no improvement after treatment (Fig. 3). 
Table 2. Spearman's $r$ correlations for Disability of arm shoulder and hand questionnaire (DASH) items responses (selected questions regarding significance and value)

\begin{tabular}{|c|c|c|c|c|c|c|c|c|c|c|c|c|c|}
\hline \multirow{2}{*}{ Variable } & \multicolumn{13}{|c|}{ Spearman's r correlation } \\
\hline & 1 & 2 & 3 & 4 & 5 & 6 & 7 & 8 & 9 & 10 & 11 & 12 & 13 \\
\hline 1. Open a tight or new jar & 1.00 & 0.74 & 0.59 & 0.45 & 0.58 & 0.50 & 0.63 & 0.53 & 0.52 & 0.68 & 0.63 & 0.50 & 0.42 \\
\hline 2. Write & 0.74 & 1.00 & 0.67 & 0.49 & 0.57 & 0.53 & 0.61 & 0.68 & 0.65 & 0.71 & 0.65 & 0.53 & 0.53 \\
\hline 3. Turn a key & 0.59 & 0.67 & 1.00 & 0.58 & 0.41 & 0.63 & 0.71 & 0.49 & 0.51 & 0.60 & 0.46 & 0.51 & 0.42 \\
\hline 4. Prepare a meal & 0.45 & 0.49 & 0.58 & 1.00 & 0.34 & 0.51 & 0.56 & 0.46 & 0.34 & 0.40 & 0.41 & 0.46 & 0.37 \\
\hline 5. Push open a heavy door & 0.58 & 0.57 & 0.41 & 0.34 & 1.00 & 0.56 & 0.48 & 0.55 & 0.53 & 0.61 & 0.76 & 0.46 & 0.50 \\
\hline 6. Place an object on a shelf above your head & 0.50 & 0.53 & 0.63 & 0.51 & 0.56 & 1.00 & 0.64 & 0.53 & 0.54 & 0.59 & 0.47 & 0.60 & 0.57 \\
\hline 7. Perform heavy household chores (e.g. wash walls/floors) & 0.63 & 0.61 & 0.71 & 0.56 & 0.48 & 0.64 & 1.00 & 0.53 & 0.51 & 0.59 & 0.54 & 0.50 & 0.33 \\
\hline 8. Gardening or yard work & 0.53 & 0.68 & 0.49 & 0.46 & 0.55 & 0.53 & 0.53 & 1.00 & 0.69 & 0.63 & 0.63 & 0.39 & 0.42 \\
\hline 9. Make a bed & 0.52 & 0.65 & 0.51 & 0.34 & 0.53 & 0.54 & 0.51 & 0.69 & 1.00 & 0.70 & 0.56 & 0.52 & 0.56 \\
\hline 10. Carry a shopping bag or briefcase & 0.68 & 0.71 & 0.60 & 0.40 & 0.61 & 0.59 & 0.59 & 0.63 & 0.70 & 1.00 & 0.71 & 0.60 & 0.55 \\
\hline 11. Carry a heavy object (over $10 \mathrm{lbs}$ ) & 0.63 & 0.65 & 0.46 & 0.41 & 0.76 & 0.47 & 0.54 & 0.63 & 0.56 & 0.71 & 1.00 & 0.50 & 0.51 \\
\hline 12. Change an overhead light bulb & 0.50 & 0.53 & 0.51 & 0.46 & 0.46 & 0.60 & 0.50 & 0.39 & 0.52 & 0.60 & 0.50 & 1.00 & 0.70 \\
\hline 13. Wash/blow dry your hair & 0.42 & 0.53 & 0.42 & 0.37 & 0.50 & 0.57 & 0.33 & 0.42 & 0.56 & 0.55 & 0.51 & 0.70 & 1.00 \\
\hline
\end{tabular}

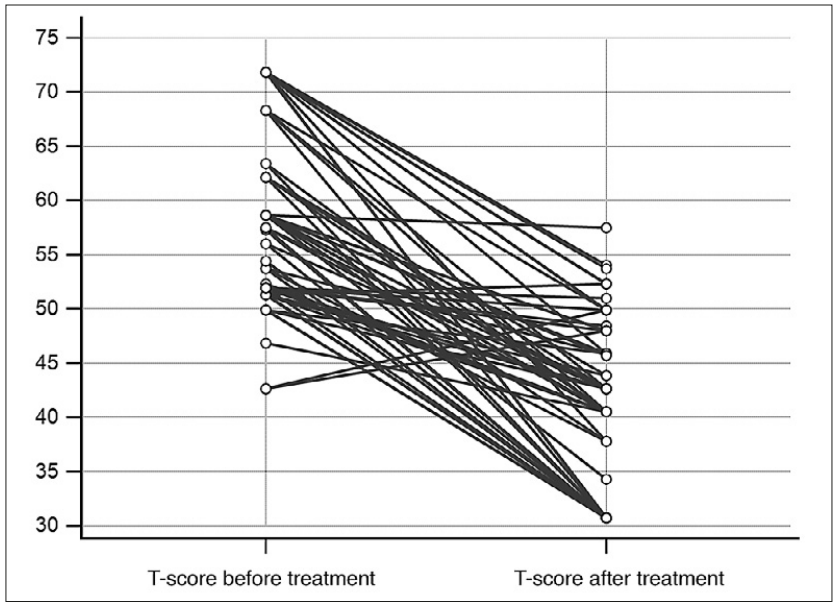

Figure 1. Dot and Line diagram of the Wilcoxon test for $\mathrm{PROMIS}^{\oplus} \mathrm{T}$-score before and after treatment

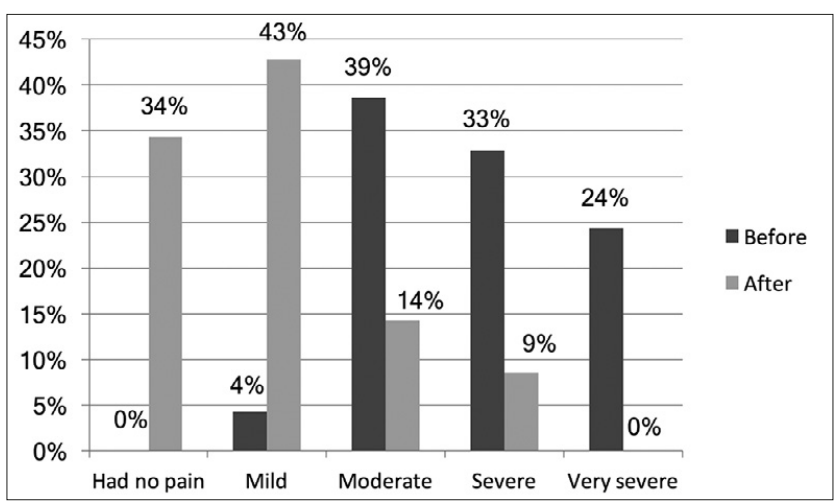

Figure 2. Pain intensity changes measured with a PROMIS ${ }^{\circledR}$ score before and after treatment (PROMIS ${ }^{\oplus}$ Pain Intensity Short Form 3a)

Features of disability regarding physical activities of the upper limb associated with CTS and the change before and after treatment were also verified using the PROMIS ${ }^{\oplus}$ Upper Extremity Questionnaire. Raw score distribution, i.e., physical activities of the upper limb before CTS treatment, was



Figure 3. Efficiency of CTS treatment measured with the PROMIS ${ }^{\circledR}$ pain scale after treatment

consistent with a normal distribution, and the CTS treatment was not consistent with a normal distribution. Detailed results for the PROMIS ${ }^{\oplus}$ Upper Extremity questionnaire are shown in Table 3. Differences before and after treatment

Table 3. T-score distribution for PROMIS ${ }^{\oplus}$ Upper Extremity results before and after treatment

\begin{tabular}{lccccc}
\hline Variable & Min. & Max. & M SD & Me & $p$ \\
\hline Before treatment & 25.00 & 76.00 & $54.54 \pm 11.16$ & 55.00 & \multirow{2}{*}{$<0.001$} \\
\hline After treatment & 18.00 & 80.00 & $67.80 \pm 9.38$ & 69.00 & \\
\hline
\end{tabular}

proved to be statistically significant $(\mathrm{p}<0.001)$, and confirmed the effectiveness of the treatment.

Results obtained with the PROMIS ${ }^{\circledR}$ pper Extremity, and PROMIS ${ }^{\oplus}$ Short Form 3a (Pain Intensity) questionnaires obtained before, and after CTS treatment clearly confirmed the effectiveness of the surgical treatment. The effectiveness of the treatment resulted in both a reduction in pain scores and reduction in disability. Based on the DASH and PROMIS $^{\circledast}$ Upper Extremity questionnaires, a strong negative correlation was observed $(\mathrm{r}=-0.64 ; \mathrm{p}<0.05)$, which indicates a high correlation between the questionnaires. 


\section{DISCUSSION}

The increased incidence of CTS among women observed in this study is similar to that described elsewhere [31, 32 ]. In a study population of 100,000 people, Bongers [33] recorded 280 cases of CTS per year among women and only 90 cases among men per year. A higher incidence of CTS has also been reported in other studies [34]. The average age of manifestation of CTS was not significantly different from other studies (including a Polish study) [35]. A group of patients aged 51-60 years ( 21 persons) and $41-50$ years of age ( 15 people) dominated in this study.

Working at the computer has been described in the literature as an important risk factor for CTS [36-46], but it is not the only cause of CTS associated with work $[4,6,47]$. In the study group of 69 respondents, up to 33 persons did not use a computer at work. Thomsen [48] concluded that there is insufficient evidence that working at the computer causes carpal tunnel syndrome. In that study, the average number of hours of work at a computer in the group of patients is very similar to other Polish studies [35].

Among the respondents, up to $87 \%$ reported a reduction in the average intensity of pain after surgery, which is consistent with the literature [49-54]. The final results of treatment evaluated using the PROMIS ${ }^{\circledR}$ Upper Extremity questionnaires proved that surgery helps to recover physical fitness of the upper limb. The use of research instruments, such as the PROMIS ${ }^{\oplus}$ Upper Extremity, PROMIS ${ }^{\oplus}$ Short Form 3a (Pain Intensity), and DASH questionnaires (translated into Polish), demonstrated favourable patient-reported results and allow for reliable comparisons with the results described in the literature.

\section{CONCLUSIONS}

The current study confirmed the efficacy of surgical treatment of CTS, which is reflected by the improved quality of life, as tested by the PROMIS ${ }^{\circledR}$ research instruments. Geographical and environmental conditions indicate that even though working with a computer is described as an important risk factor for CTS, the presented study group showed a predominance of factors that were unrelated to working at a computer. CTS also occurred among people working physically, and even among unemployed individuals.

Surgical release of the median nerve in nearly $90 \%$ of patients provided a reduction in average pain intensity. The existence of a statistically significant, strong, negative correlation $(\mathrm{r}=-0.64 ; \mathrm{p}<0.05)$ between the results obtained in the questionnaires DASH and PROMIS ${ }^{\oplus}$ Upper Extremity has been demonstrated.

\section{Declarations of interest: None declared}

This study did not receive any specific grant from funding agencies in the public, commercial, or non-profit sectors.

\section{Acknowledgments}

Authors are thankful for the statistical analysis support to Mr. Emanuel Tataj M.S. We would like to thank Editage [http://www.editage.com] for editing and reviewing this manuscript for English language.

\section{REFERENCES}

1. Aroui H, Merchaoui I, Adnene Henchi M, Rassas I, Belhadj N, Chaari $\mathrm{N}$, et al. Medical and professional consequences of occupational carpal tunnel syndrome. Ann Phys Rehabil Med. 2016; 59S: e114. doi: 10.1016/j. rehab.2016.07.256. PubMed PMID: 27676736.

2. Mediouni Z, Bodin J, Dale AM, Herquelot E, Carton M, Leclerc A, et al. Carpal tunnel syndrome and computer exposure at work in two large complementary cohorts. BMJ Open. 2015; 5(9): e008156. doi: 10.1136/ bmjopen-2015-008156. PubMed PMID: 26353869; PubMed Central PMCID: PMCPMC4567686.

3. Newington L, Harris EC, Walker-Bone K. Carpal tunnel syndrome and work. Best Pract Res Clin Rheumatol. 2015; 29(3): 440-53. doi: 10.1016/j.berh.2015.04.026. PubMed PMID: 26612240; PubMed Central PMCID: PMC4759938.

4. Zyluk A. Is carpal tunnel syndrome an occupational disease? A review. Pol Orthop Traumatol. 2013; 78: 121-6. PubMed PMID: 23708319.

5. Spahn G, Wollny J, Hartmann B, Schiele R, Hofmann GO. [Metaanalysis for the evaluation of risk factors for carpal tunnel syndrome (CTS) Part II. Occupational risk factors]. Zeitschrift fur Orthopadie und Unfallchirurgie. 2012; 150(5): 516-24. doi: 10.1055/s-0032-1315346. PubMed PMID: 23076750.

6. Giersiepen K, Spallek M. Carpal tunnel syndrome as an occupational disease. Dtsch Arztebl Int. 2011; 108(14): 238-42. doi: 10.3238/ arztebl.2011.0238. PubMed PMID: 21547163; PubMed Central PMCID: PMCPMC3087121.

7. Shiri R, Falah-Hassani K. Computer use and carpal tunnel syndrome: A meta-analysis. J Neurol Sci. 2015; 349(1-2): 15-9. doi: 10.1016/j. jns.2014.12.037. PubMed PMID: 25582979.

8. Bena A, Mamo C, Argentero O, Baratti A, Bruno S, Ferraris F, et al. [Carpal tunnel syndrome (CTS) in the Piedmont Region: regional incidence and prevalence of CTS based on hospital records of patients who underwent surgery]. Med Lav. 2007; 98(4): 320-30. PubMed PMID: 17679345.

9. Dale AM, Harris-Adamson C, Rempel D, Gerr F, Hegmann K, Silverstein B, et al. Prevalence and incidence of carpal tunnel syndrome in US working populations: pooled analysis of six prospective studies. Scandinavian journal of work, environment \& health. 2013; 39(5): 495-505. doi: 10.5271/sjweh.3351. PubMed PMID: 23423472; PubMed Central PMCID: PMC4042862.

10. Ferry S, Pritchard T, Keenan J, Croft P, Silman AJ. Estimating the prevalence of delayed median nerve conduction in the general population. Br J Rheumatol. 1998; 37(6): 630-5. PubMed PMID: 9667616.

11. Conzen C, Conzen M, Rubsamen N, Mikolajczyk R. Predictors of the patient-centered outcomes of surgical carpal tunnel release - a prospective cohort study. BMC Musculoskelet Disord. 2016; 17: 190. doi: 10.1186/s12891-016-1046-3. PubMed PMID: 27121725; PubMed Central PMCID: PMCPMC4848854.

12. Khan AA, Ali H, Ali K, Muhammad G, Rashid B, Gul N, et al. Outcome of Open Carpal Tunnel Release Surgery. J Ayub Med Coll Abbottabad. 2015; 27(3): 640-2. PubMed PMID: 26721028.

13. Louie DL, Earp BE, Collins JE, Losina E, Katz JN, Black EM, et al. Outcomes of open carpal tunnel release at a minimum of ten years. J Bone Joint Surg Am. 2013; 95(12): 1067-73. doi: 10.2106/JBJS.L.00903. PubMed PMID: 23783202; PubMed Central PMCID: PMCPMC3748987.

14. Kohanzadeh S, Herrera FA, Dobke M. Outcomes of open and endoscopic carpal tunnel release: a meta-analysis. Hand (N Y). 2012; 7(3): 247-51. doi: 10.1007/s11552-012-9413-5. PubMed PMID: 23997726; PubMed Central PMCID: PMCPMC3418358.

15. Louie D, Earp B, Blazar P. Long-term outcomes of carpal tunnel release: a critical review of the literature. Hand (N Y). 2012; 7(3): 242-6. doi: 10.1007/s11552-012-9429-x. PubMed PMID: 23997725; PubMed Central PMCID: PMCPMC3418353.

16. Golicki D, Krzysiak M, Strzelczyk P. Translation and cultural adaptation of the Polish version of the Disabilities of the Arm, Shoulder and Hand (DASH) and QuickDASH questionnaires. Ortopedia, traumatologia, rehabilitacja. 2014; 16(4): 387-95. doi: 10.5604/15093492.1119616. PubMed PMID: 25404628.

17. Overbeek CL, Nota SP, Jayakumar P, Hageman MG, Ring D. The PROMIS physical function correlates with the QuickDASH in patients with upper extremity illness. Clin Orthop Relat Res. 2015; 473(1): 311-7. doi: 10.1007/s11999-014-3840-2. PubMed PMID: 25099262; PubMed Central PMCID: PMC4390943.

18. T.M. B. Abstracts iProceedings Booklet 2013. Available from: http:// www.medicine 20 congress.com/ocs/public/conferences/med20/ schedConfs/med2013/iproceedings-medicine2013london.pdf. 
19. Available from: http://www.healthmeasures.net/explore-measurementsystems/promis.

20. Cella D, Yount S, Rothrock N, Gershon R, Cook K, Reeve B, et al. The Patient-Reported Outcomes Measurement Information System (PROMIS): progress of an NIH Roadmap cooperative group during its first two years. Med Care. 2007; 45(5 Suppl 1): S3-S11. doi: 10.1097/01 mlr.0000258615.42478.55. PubMed PMID: 17443116; PubMed Central PMCID: PMCPMC2829758.

21. Reeve BB, Hays RD, Bjorner JB, Cook KF, Crane PK, Teresi JA, et al. Psychometric evaluation and calibration of health-related quality of life item banks: plans for the Patient-Reported Outcomes Measurement Information System (PROMIS). Med Care. 2007; 45(5 Suppl 1): S22-31. doi: 10.1097/01.mlr.0000250483.85507.04. PubMed PMID: 17443115.

22. Amtmann D, Cook KF, Jensen MP, Chen WH, Choi S, Revicki D, et al. Development of a PROMIS item bank to measure pain interference. Pain. 2010; 150(1): 173-82. doi: 10.1016/j.pain.2010.04.025. PubMed PMID: 20554116; PubMed Central PMCID: PMCPMC2916053.

23. Cook KF, Schalet BD, Kallen MA, Rutsohn JP, Cella D. Establishing a common metric for self-reported pain: linking BPI Pain Interference and SF-36 Bodily Pain Subscale scores to the PROMIS Pain Interference metric. Quality of life research: an international journal of quality of life aspects of treatment, care and rehabilitation. 2015; 24(10): 2305-18 doi: 10.1007/s11136-015-0987-6. PubMed PMID: 25894063; PubMed Central PMCID: PMCPMC4567433.

24. Cook KF, Jensen SE, Schalet BD, Beaumont JL, Amtmann D, Czajkowski $S$, et al. PROMIS measures of pain, fatigue, negative affect, physical function, and social function demonstrated clinical validity across a range of chronic conditions. Journal of clinical epidemiology. 2016; 73: 89-102. doi: 10.1016/j.jclinepi.2015.08.038. PubMed PMID: 26952842; PubMed Central PMCID: PMCPMC5131708.

25. Jensen RE, Moinpour CM, Potosky AL, Lobo T, Hahn EA, Hays RD, et al. Responsiveness of 8 Patient-Reported Outcomes Measurement Information System (PROMIS) measures in a large, community-based cancer study cohort. Cancer. 2016. doi: 10.1002/cncr.30354. PubMed PMID: 27696377.

26. Askew RL, Cook KF, Keefe FJ, Nowinski CJ, Cella D, Revicki DA, et al. A PROMIS Measure of Neuropathic Pain Quality. Value Health. 2016; 19(5): 623-30. doi: 10.1016/j.jval.2016.02.009. PubMed PMID: 27565279; PubMed Central PMCID: PMCPMC5002873.

27. Hung M, Clegg DO, Greene T, Saltzman CL. Evaluation of the PROMIS physical function item bank in orthopaedic patients. Journal of orthopaedic research: official publication of the Orthopaedic Research Society. 2011; 29(6): 947-53. doi: 10.1002/jor.21308. PubMed PMID: 21437962.

28. Witter JP. The Promise of Patient-Reported Outcomes Measurement Information System-Turning Theory into Reality: A Uniform Approach to Patient-Reported Outcomes Across Rheumatic Diseases. Rheum Dis Clin North Am. 2016; 42(2): 377-94. doi: 10.1016/j.rdc.2016.01.007. PubMed PMID: 27133496.

29. Terwee CB, Roorda LD, de Vet HC, Dekker J, Westhovens R, van Leeuwen J, et al. Dutch-Flemish translation of 17 item banks from the patient-reported outcomes measurement information system (PROMIS). Quality of life research: an international journal of quality of life aspects of treatment, care and rehabilitation. 2014; 23(6): 1733-41. doi: 10.1007/s11136-013-0611-6. PubMed PMID: 24402179.

30. Polska S. Statistica. Available from: http://www.statsoft.pl/Programy/ Ogolna-charakterystyka/Ogolna-filozofia-Statistica.

31. Valachi B. Musculoskeletal health of the woman dentist: distinctive interventions for a growing population. Journal of the California Dental Association. 2008; 36(2): 127-32. PubMed PMID: 18411975.

32. Ricco M, Cattani S, Signorelli C. Personal risk factors for carpal tunnel syndrome in female visual display unit workers. International journal of occupational medicine and environmental health. 2016; 29(6): 927-36. doi: 10.13075/ijomeh.1896.00781. PubMed PMID: 27869243.

33. Bongers FJ, Schellevis FG, van den Bosch WJ, van der Zee J. Carpal tunnel syndrome in general practice (1987 and 2001): incidence and the role of occupational and non-occupational factors. Br J Gen Pract. 2007; 57(534): 36-9. PubMed PMID: 17244422; PubMed Central PMCID: PMCPMC2032698.

34. Newington L HE, Walker-Bone K. Carpal Tunnele Syndrome and Work 2015. Available from: http://www.ncbi.nlm.nih.gov/pubmed/26612240.

35. Lewańska M. W-KE, Walusiak-Skorupa J. Analiza czynników etiologicznych zespołu cieśni nadgarstka w populacji osób pracujących z zawodowo z użyciem komputera 2013. Available from: http://www. imp.lodz.pl/upload/oficyna/artykuly/pdf/full/---2013_1_Lewanska. pdf.
36. Ali KM, Sathiyasekaran BW. Computer professionals and Carpal Tunnel Syndrome (CTS). Int J Occup Saf Ergon. 2006; 12(3): 319-25. doi: 10.1080/10803548.2006.11076691. PubMed PMID: 16984790.

37. Andersen JH, Thomsen JF, Overgaard E, Lassen CF, Brandt LP, Vilstrup I, et al. Computer use and carpal tunnel syndrome: a 1-year follow-up study. JAMA. 2003; 289(22): 2963-9. doi: 10.1001/jama.289.22.2963. PubMed PMID: 12799404.

38. Andersen JH, Thomsen JF, Overgaard E, Lassen CF, Brandt LP, Vilstrup I, et al. [Computer use and carpal tunnel syndrome: a 1-year followup study]. Ugeskrift for laeger. 2004; 166(33): 2804-7. PubMed PMID: 15344861.

39. Atroshi I, Gummesson C, Ornstein E, Johnsson R, Ranstam J. Carpal tunnel syndrome and keyboard use at work: a population-based study. Arthritis and rheumatism. 2007; 56(11): 3620-5. doi: 10.1002/art.22956. PubMed PMID: 17968917.

40. Bleecker ML. The frequency of carpal tunnel syndrome in computer users at a medical facility. Neurology. 2002; 58(8): 1313-4; author reply 4-5. PubMed PMID: 11973823.

41. Eleftheriou A, Rachiotis G, Varitimidis SE, Koutis C, Malizos KN, Hadjichristodoulou C. Cumulative keyboard strokes: a possible risk factor for carpal tunnel syndrome. J Occup Med Toxicol. 2012; 7(1): 16. doi: 10.1186/1745-6673-7-16. PubMed PMID: 22856674; PubMed Central PMCID: PMC3480831.

42. Franklin GM. The frequency of carpal tunnel syndrome in computer users at a medical facility. Neurology. 2002; 58(8): 1314; author reply -5. PubMed PMID: 11973826.

43. Hedge A. Computer use and risk of carpal tunnel syndrome. JAMA. 2003; 290(14): 1854; author reply -5. doi: 10.1001/jama.290.14.1854-a. PubMed PMID: 14532310.

44. Hettinger L. The frequency of carpal tunnel syndrome in computer users at a medical facility. Neurology. 2002; 58(8): 1313; author reply 4-5. PubMed PMID: 11971115.

45. Nathan PA, Meadows KD, Istvan JA. Computer use and risk of carpal tunnel syndrome. JAMA. 2003; 290(14): 1853-4; author reply 4-5. doi: 10.1001/jama.290.14.1853-b. PubMed PMID: 14532309.

46. Thomsen JF, Gerr F, Atroshi I. Carpal tunnel syndrome and the use of computer mouse and keyboard: a systematic review. BMC Musculoskelet Disord. 2008; 9:134. Epub 2008/10/08. doi: 10.1186/14712474-9-134-1471-2474-9-134 [pii]. PubMed PMID: 18838001; PubMed Central PMCID: PMC2569035.

47. Stocks SJ, McNamee R, van der Molen HF, Paris C, Urban P, Campo G, et al. Trends in incidence of occupational asthma, contact dermatitis, noise-induced hearing loss, carpal tunnel syndrome and upper limb musculoskeletal disorders in European countries from 2000 to 2012. Occup Environ Med. 2015; 72(4): 294-303. doi: 10.1136/ oemed-2014-102534. PubMed PMID: 25575531.

48. Thomsen J. F. GF, Atroshi I. Carpal tunnel syndrome and the use of computer mouse and keyboard: A systematic review 2008. Available from: http://www.ncbi.nlm.nih.gov/pmc/articles/PMC2569035/.

49. Soltani AM, Allan BJ, Best MJ, Mir HS, Panthaki ZJ. A systematic review of the literature on the outcomes of treatment for recurrent and persistent carpal tunnel syndrome. Plastic and reconstructive surgery. 2013; 132(1): 114-21. doi: 10.1097/PRS.0b013e318290faba. PubMed PMID: 23806914.

50. Shi Q, MacDermid JC. Is surgical intervention more effective than nonsurgical treatment for carpal tunnel syndrome? A systematic review. J Orthop Surg Res. 2011; 6: 17. doi: 10.1186/1749-799X-6-17. PubMed PMID: 21477381; PubMed Central PMCID: PMC3080334.

51. Iida J, Hirabayashi H, Nakase H, Sakaki T. Carpal tunnel syndrome: electrophysiological grading and surgical results by minimum incision open carpal tunnel release. Neurol Med Chir (Tokyo). 2008; 48(12): 554-9. PubMed PMID: 19106493.

52. Jerosch-Herold C, Leite JC, Song F. A systematic review of outcomes assessed in randomized controlled trials of surgical interventions for carpal tunnel syndrome using the International Classification of Functioning, Disability and Health (ICF) as a reference tool. BMC musculoskeletal disorders. 2006; 7: 96. doi: 10.1186/1471-2474-7-96. PubMed PMID: 17147807; PubMed Central PMCID: PMC1713237.

53. Hobby JL, Venkatesh R, Motkur P. The effect of age and gender upon symptoms and surgical outcomes in carpal tunnel syndrome. J Hand Surg. 2005; 30(6): 599-604. doi: 10.1016/j.jhsb.2005.07.005. PubMed PMID: 16143435.

54. DeStefano F, Nordstrom DL, Vierkant RA. Long-term symptom outcomes of carpal tunnel syndrome and its treatment. J Hand Surg. 1997; 22(2): 200-10. doi: 10.1016/S0363-5023(97)80152-9. PubMed PMID: 9195415. 